\title{
Plasticization Effect on the Photodegradation of Poly (4-Chlorostyrene) and Poly (4-Bromostyrene) Films
}

\author{
Khalid E. Al Ani ${ }^{1}$, Afrah Essa Ramadhan ${ }^{2}$ \\ ${ }^{1}$ Department of Petroleum Engineering, The British University of Science and Technology, Irbil, Iraq; ${ }^{2}$ Department of Industrial \\ Chemistry, Institute of Technology, Baghdad, Iraq. \\ E-mail: khalidalani44@yahoo.com
}

Received September $15^{\text {th }}, 2010$; revised October $16^{\text {th }}, 2010$; accepted November $19^{\text {th }}, 2010$.

\begin{abstract}
The photodegradation of thin films of poly (4-chlorostyrene) and poly (4-bromostyrene) with $265 \mathrm{~nm}$ radiation in the presence of oxygen and as a function of irradiation time has been studied mainly using fluorescence, FT-IR, and UV-VIS spectroscopic techniques. The influence of phthalate and terephthalate plasticizers on photo-oxidative degradation was also investigated. Phthalate and terephthalate-plasticizers were found to increase the photodegradation processes in polymeric chains. On the other hand, the intensity of absorption was also found to increase with irradiation time and in the intensity of a new absorption band at longer wavelength. The appearance of new fluorescence bands in the irradiated polymer films can well indicate a possibility of photodegradation of polymer films. In addition, the observed increase in the intensities of the carbonyl and hydroxyl regions of the FT-IR spectra, providing evidence for the photodegradation as well as the photo-oxidation of polymeric chains. The increase in the analyzed ranges was attributed to the formation of alcohols, aliphatic ketones and to the increase in the number of $(C=C)$ that resulted from hydrogen abstraction during chains-scission.
\end{abstract}

Keywords: Excimer Fluorescence, Poly (4-Bromostyrene), Poly (4-Chlorostyrene), Photodegradation Kinetics, Phthalate Plasticizers

\section{Introduction}

The study of degradation and stabilization of polymers is significant for both practical and theoritical viewpoints [1]. The thermal behaviour of halogenated polymers received a considerable attention, owing mainly to the industrial importance of these polymers [2-6]. Indeed thermal degradation behavior of poly (4-bromostyrene) (PBS), and Poly (4-chlorostyrene) (PCS), has been found to be closely analogous to that of polystyrene (PS) [7]. A blend of PBS with poly (methyl methacrylate) showed some interaction during degradation resulting in some stabilization of the PBS. Thus, bromonation and chlrorination in polymer chromophore, losse the backbone helide as hydrogen helide at high temperature or during irradiation. The resulting unsaturation in the polymer backbone provides points of weakness for chain scission, which occurs at lower temperature than for polystyrene [8]. Ring-brominated polystyrene is less stable than ring chlorinated polystyrene, as it lacks the backbone haloge- nations which are unavoidable in the ring chlorination in polystyrene. The halogenated polystyrenes have fairly similar thermal stability to polystyrene and degrade in essentially the same way giving mainly the monomer, as well as styrene and hydrogen halide [2].

The knowledge of photodegradation process in polymers is quite essential from a practical point of view, especially when it comes to its outdoor applications. Weathering of polymer materials which involves physical and chemical changes during the exposure of polymer to light and heat [9-11] is often investigated in accelerated conditions, though they can significantly differ from that in a natural environment [12]. It should be indicated that irradiated polymeric materials undergo a series of oxidative reactions that lead to photochemical degradation [13-15] with consequences like brittleness, loss of brightness, and color changes. Besides the cross-linking processes, a number of other changes may take place in polymeric chains during photodegradation $[16,17]$. 
Many investigations concerning the photodegradation of polystyrene [18-20] and substituted polystyrene [21] have been carried out. It has been reported that photodegradation in PS films occurs when irradiated with UV-radiation; under atmospheric oxygen. Hence the initiation of photo-oxidation is expected to result from the absorption by polymeric chromophores. From the latter process, a number of different photoproducts were reported. More specifically, hydro peroxides, carbonyl and hydroxyl compounds were the main products that resulted from the photo-oxidation of PS films [22-25].

On the other hand polymeric additives were found to accelerate the radiation-induced degradation of PS and poly (4-substituted styrene) films (SPS) [20]. It was also found that the photo-stability of PS was reduced by the addition of bromine-containing flame retardants, and appeared to depend upon the chemical structure of the polymeric additive [19]. It was reported that the photodegradation of the PS containing carbonyl group was increased with the increase in the time of irradiation. The changes in the average molecular weight in photo-oxidized PS were produced as a consequence of chain dissociation by the Norrish Type II reaction [26].

The aim of this work is to examine the photostability of pure and blended PBS and PCS films, which contain a small amount of doped dimethyl terephthalate, diethyl terephthalate, dioctyl terephthalate, dibutyl phthalate and dioctyl phthalate plasticizers upon UV-irradiation. The present study also seeks to check if plasticization affects the photostability of these polymers in solid films, and to investigate the effect of the bulkiness of plasticizer molecules on the photodegradation processes of PBS and PCS in films.

The photodegradation processes of the irradiated polymer have been characterized by UV-visible, fluorescence, and FT-IR spectroscopic techniques. The efficiency of photodegradation of PCS and PBS is compared to that of blended polystyrene with polymeric additives.

\section{Experimental Part}

\subsection{Materials}

The samples of PCS and PBS were supplied by AcrossOrganics with high purity, PCS, $(\mathrm{Mw}=65,000, \mathrm{Mn}=$ 31,000), and PBS, $(\mathrm{Mw}=7,500, \mathrm{Mn}=3,300)$ [27]. Spectroscopic-quality, dichloroethane was found to give no detectable absorption in the range $250-400 \mathrm{~nm}$, and was used in preparation of solid films. It was purchased from Fluka GMBH and was used as received. The used plasticizes were dimethyl terephthalate (DMT), diethyl terephthalate (DET), dioctyl terephthalate (DOT), dibutyl phthalate (DBP), and dioctyl phthalate (DOP), were of high-purity of $99.8 \%$ which was purchased from AcrossOrganics. They were also found to give no detectable absorption or emission in the range $265-400 \mathrm{~nm}$.

\subsection{Preparation of Plasticized Polymeric Solid Films}

PCS and PBS thin films with thickness of approximately $0.02 \mathrm{~mm}$ were prepared by solution casting of $20 \mathrm{wt} . \%$ polymer in dichloroethane solvent (DCE) on a spectroscopic window (quartz plate of $1.0 \mathrm{~mm} \times 20 \mathrm{~mm}$ diameter). Moreover, about $0.02 \mathrm{~mm}$ thick PCS and PBS- plasticizer films, containing different wt.\% plasticizers were prepared by solution casting of a 20 wt. $\%$ polymer + added plasticizer, in DCE solvent. All solid films were dried in a vacuum oven at $300 \mathrm{~K}$ for $6 \mathrm{hrs}$, as to ensure the complete removal of solvent traces [27].

\subsection{Absorption and Fluorescence Spectra Measurements}

Fluorescence spectra were recorded on JASCO FP 6500 Spectrofluorometer for each of the prepared samples. The parameters were constant for all measurements, and the excitation wavelength was $265 \mathrm{~nm}$. The emission wavelength range was $270-500 \mathrm{~nm}$, and all fluorescence spectra of the solid films were obtained using a thermostated solid sample holder at $298 \mathrm{~K}$.

The UV absorption spectra for PCS and PBS solid films were recorded before and immediately after UV irradiation with a Cary 100 Bio UV-visible Spectrophotometer at $298 \mathrm{~K}$.

\subsection{Irradiation of Polymeric Films}

PCS and PBS solid films were exposed to UV-radiation for different intervals of time, from (0.0-4.0 hrs), using a JASCO spectrometer with a built in Hydrogen-Xenon lamp (6808-J007A model number ESC-333). It is supported with monochromator of holographic grating with 1800 grooves $/ \mathrm{mm}$. Each film was irradiated for different interval of time with a monochromatic light of $265 \mathrm{~nm}$ in a thermostated solid sample holder in presence of air. The intensity of incident radiation was $\left(4.9 \mathrm{~mW} / \mathrm{cm}^{2}\right)$, and the distance between light source and samples was $(5 \mathrm{~cm})$.

\subsection{FT-IR Spectroscopy}

The FT-IR-spectroscopy system that was employed in this work was NICOLET-MAGNA-IR-560 spectrometer, while the transmission mode was employed in these measurements. The FT-IR spectra were recorded for the irradiated and the non-irradiated films, whereas the transmittance was plotted as function of the wavenumbers.

\subsection{Calculation of $\left.\left.I^{0}{ }_{[P H-P H}\right]^{*} / I_{[P H-P H}\right]^{*}$ Ratios}

In an earlier work, an equation was invented to calculate the fluorescence quenching effect and the photo quenching rate constant as function of increase in exposure time 
[37]. The ratio of $\left.I_{[P H-P H}^{o} / I_{[P H-P H}\right]^{*}$ Was found to increase by the increase in irradiation time to polymeric films. $I^{O}$ $[\mathrm{PH}-\mathrm{PH}]^{*}$ is the intensity of excimer fluorescence of pure or doped polymer at zero time of irradiation, whereas, $\left.I_{[P H-P H}\right]^{*}$ is the intensity of excimer emission of pure or doped polymer at different intervals of exposure time to UV - irradiation.

$$
\begin{aligned}
& I_{[P H-P H]^{*}}^{o} / I_{[P H-P H]^{*}}=1+\left(k_{P Q}^{\prime} \times A\right) \times(t) \\
& I_{[P H-P H]^{*}}^{o} / I_{[P H-P H]^{*}}=1+\left(k_{P Q}\right) \times t
\end{aligned}
$$

where $[A]=$ number of (photons/s) absorbed by polymeric chromophores.

$t=$ time of irradiation in $\mathrm{s}$.

$k_{P Q}=\left(k_{P Q}^{\prime} \times A\right)=$ photo-quenching rate constant.

In the photo-quenching processes, if we assume that the number of photons released from the light source and absorbed by solid films is constant (A), then, according to Equation (2), we can plot $\left.I_{[P H-P H]^{*}}^{0} / I_{[P H-P H}\right]^{*}$ - values against the time of irradiations. From the plot, which is similar to that of Stern-Volmer plot, we can evaluate the photo-quenching rate constant $\left(k_{P Q}\right)$.

\section{Results and Discussion}

\subsection{Effect of UV-Irradiation on Absorption Spectra of Pure and Blended PCS and PBS Films}

The effect of UV-light irradiation on the efficiency of photochemical processes in films of pure PCS and PBS as well as in blended polymers films with $1-4 \%$ of phthalates or terephthalate plasticizers were studied by their absorption spectra. The absorption spectra of irradiated PCS and PBS films for different exposure time show that the absorbance increases markedly at wavelength above $295 \mathrm{~nm}$ for PCS and above $290 \mathrm{~nm}$ for PBS, as shown in Figure 1 for PCS, and Figure 2 for PBS.

As in the case of many vinyl polymers, the chromophoric units, which are responsible for UV-light energy absorption, are the basic backbone structure of the polymer [13], whereas in PBS and PCS, the para-substituted styrene groups, are the chromophoric units that are responsible for absorption of the $265 \mathrm{~nm}$ radiation, and of course is affected by the chemical structure of the constituents. The effect of the irradiation on the absorption spectra of both PCS and PBS films, in presence of air resulted in a gradual increase in the intensity of the absorption spectra with the increase in exposure time, as shown in Figure 1(a), and Figure 2(a) for PCS and PBS, respectively. The irradiated films of blended PCS and PBS showed a higher increase in the intensity of absorption spectra as shown in Figure 1(b) and Figure 2(b) respectively. The increase in the absorption intensity after irradiation for 2 hours, with the increase in added DOT, suggests that added plasticizers is either enhancing the photochemical degradation of PCS and PBS films, or interact with the excited polymeric chromophores. Moreover, the increase of absorption of DOT doped polymer films, with the increase in irradiation time; suggest that photo-oxidation and photodegradation processes are the main dominating processes in the irradiated PCS and PBS solid films [28].

\subsection{Effect of UV-Irradiation Time on Fluorescence Spectra of Pure and Blended PCS and PBS Films}

A number of studies have provided information about photodegradation of para-substituted polystyrenes [29,30], but none of these have dealt with the photodegradation of plasticized PCS and PBS in solid films. It is well known that irradiation of para substituted polystyrene leads to the generation of aromatic free radicals that can initiate photodegradation of polymeric chains $[31,32]$. The effects of light energy on the stability of pure and blended PCS and PBS were studied by measuring their emission spectra before and after irradiation. The fluorescence spectra of PCS, before and after the exposure of solid films

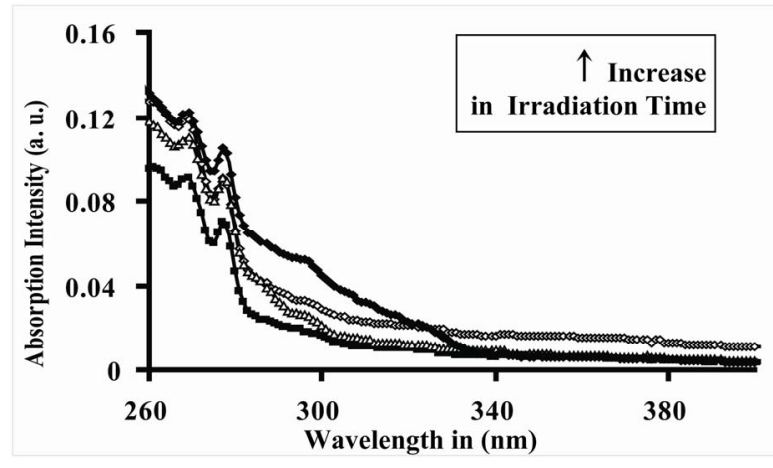

(a)

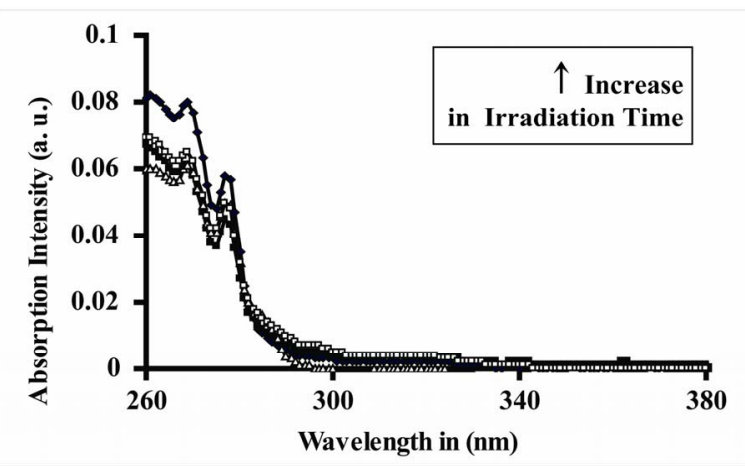

(b)

Figure 1. Absorption spectra of PCS, (a) pure polymer film, and (b) blended PBSwith 4.0\% DOT, irradiated at 0.0, 1.0, 2.0 , and $4.0 \mathrm{hrs}$ at $\lambda_{\text {ext }}=265 \mathrm{~nm}$. 


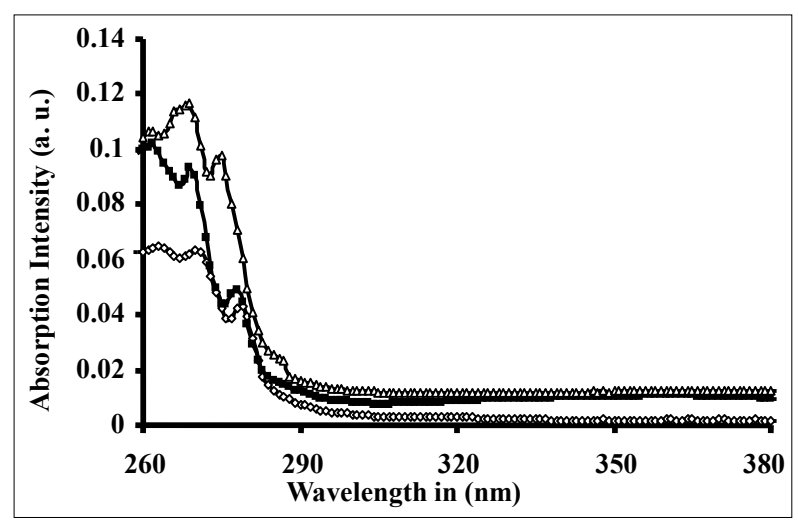

(a)

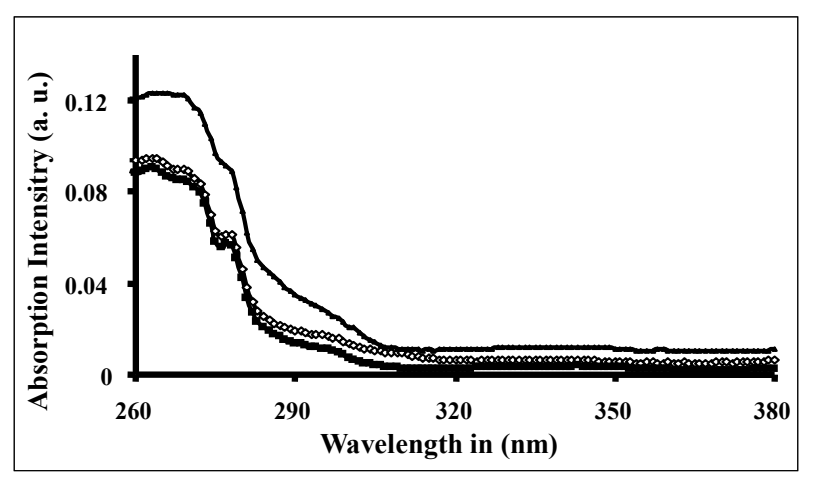

(b)

Figure 2. Absorption spectra of PBS, (a) pure polymer film, and (b) blended PBSwith 4.0\% DOT, irradiated at 0.0, 2.0, and $4.0 \mathrm{hrs}$, at $\lambda_{\mathrm{ext}}=265 \mathrm{~nm}$.

to UV-radiation for different intervals of time are presented in Figure 3.

It can be noticed from the fluorescence spectra of irradiated pure PCS that the increase in the time of UV-exposure causing an increase in the intensity of two new fluorescence bands at maxima of about $362 \mathrm{~nm}$ and $378 \mathrm{~nm}$. This process was accompanied by the decrease in the intensity of the excimer fluorescence band. Although the two new fluorescence bands are not identified, one can conclude that the increase in the time of irradiation caused an increase the photodegradation of the polymeric chains, as shown in Figure 3(a). On the other hand, the fluorescence spectra of blended PCS films, showed different characteristics in comparison with that of irradiated pure PCS films. That is, addition of phthalates and terephthalate plasticizers caused quenching to the excimer fluorescence without the formation of exciplex emission [33,34]. As can be seen in Figures 3(b,c), for the blended PCS with $2.0 \%$ and $4.0 \%$ DBP, the increase in exposure time of blended PCS films caused a decrease in the excimer fluorescence band $\lambda_{\max }=312 \mathrm{~nm}$ and an increase in the intensity of a new broad bands at $\lambda_{\max }=362,380,452$, and $471 \mathrm{~nm}$. The intensity of the fluorescence bands were also found to increase with increasing in the exposure irradiation time. From the changes in the fluorescence spectra of blended PCS films, one can conclude that irradiation of blended PCS films may initiate a photochemical reaction between plasticizer molecules and polymeric chromophores as well as photodegradation of polymeric chains that can be initiated by free radical formation.films, showed different characteristics in comparison with that of irradiated pure PCS films. That is, addition of phthalates and terephthalate plasticizers caused

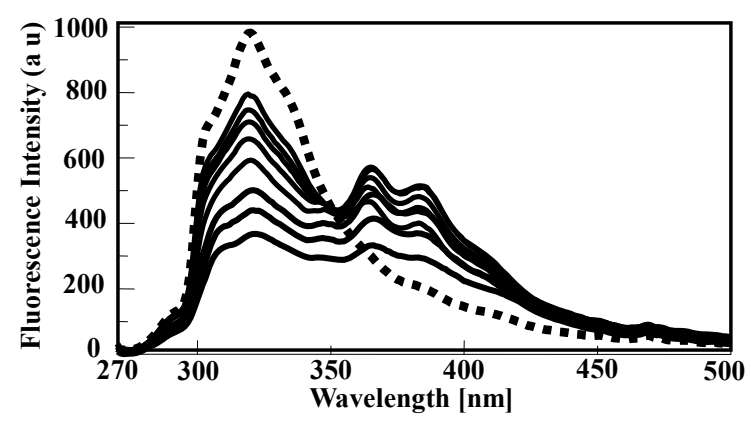

(a)

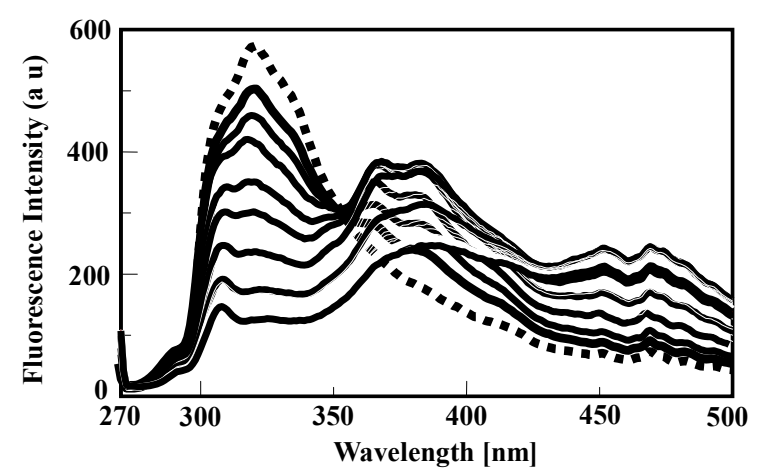

(b)

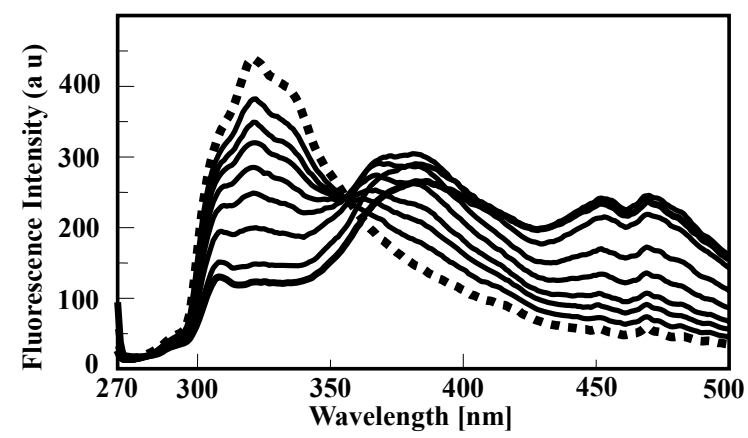

(c)

Figure 3. Effect of irradiation time on excimer fluorescence intensity of PCS, non-irradiated film (dotted line), and irradiated films (solid lines). (a) Pure PCS film, (b) PCS film blended with $2.0 \%$ DBP, and (c) PCS film blended with $4.0 \%$ DBP at $(0.0,10,15,20,30,40,60.80$ and $100 \mathrm{~min})$, from top to bottom. 
quenching to the excimer fluorescence without the formation of exciplex emission [33,34]. As can be seen in Figures 3(b,c), for the blended PCS with $2.0 \%$ and $4.0 \%$ DBP, the increase in exposure time of blended PCS films caused a decrease in the excimer fluorescence band $\lambda_{\max }$ $=312 \mathrm{~nm}$ and an increase in the intensity of a new broad bands at $\lambda_{\max }=362,380,452$, and $471 \mathrm{~nm}$. The intensity of the fluorescence bands were also found to increase with increasing in the exposure irradiation time. From the changes in the fluorescence spectra of blended PCS films, one can conclude that irradiation of blended PCS films may initiate a photochemical reaction between plasticizer molecules and polymeric chromophores as well as photodegradation of polymeric chains that can be initiated by free radical formation.

Furthermore, blending of PCS films with DBP or with DOP plasticizer caused higher excimer fluorescence quenching effect than that observed with blending with DMT, DET and DOT plasticizers.

The same observations were observed in the irradiation of PBS film at different intervals of exposure time. This process was also accompanied by the decrease in the intensity of the excimer fluorescence band as shown in Figure 4(a).

As shown in Figures 4(b,c), for the blended PBS with $2.0 \%$ and $4.0 \%$ DOT, the increase in exposure time of blended PBS films caused a decrease in the excimer fluorescence band at $\lambda_{\max }=304 \mathrm{~nm}$, and an increase in the intensity of a new broad bands at $\lambda_{\max }=353$, and 420 $\mathrm{nm}$. The intensity of the latter fluorescence bands were also found to increase by increasing the exposure time of irradiation.

Almost the same observations were noticed in blending of PBS with DMT, DET, DBP and DOP plasticizers. The structure in the fluorescence spectra at longer wavelength is considered to be a noise, as the quantum yield of PBS fluorescence is low, which was reported to be (0.023) [35].

Based on the reported works by Torikai et al. [19] and Geuskens et al. [36] on photo-irradiated polystyrene, the emission bands of 362,425 , and $477 \mathrm{~nm}$ corresponded to polyene unit structures and were defined by $n=1,2$, and 3 respectively. As shown in Figures $(\mathbf{3 , 4})$, although the formation of the new emission bands have no clear maxima, the position of these bands were closed to that reported by Geuskens et al. [36] indicating the possibility of formation of polyene structure units.

The kinetic treatments to the fluorescence quenching of PCS by the increase in the amount of added DBP, DMT and DET, plasticizers are shown in Figures 5 (a-c).

The fluorescence quenching of PBS by the added DMT, DET and DOP by the increase in the amount of added plasticizers are shown in Figures 6 (a-c).

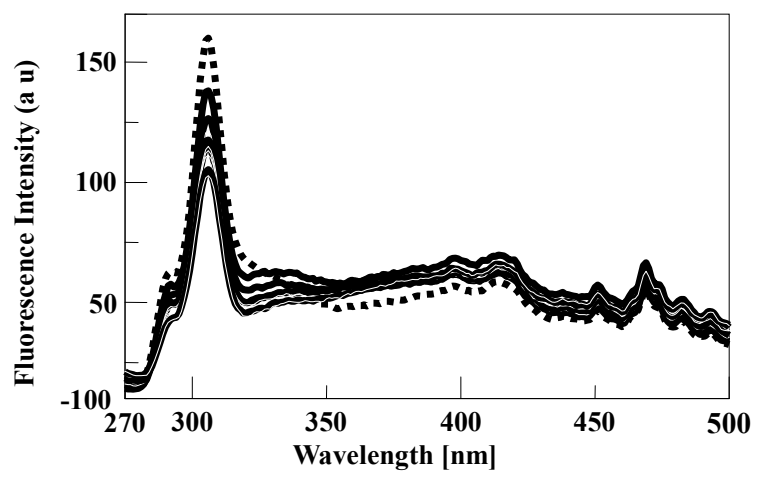

(a)

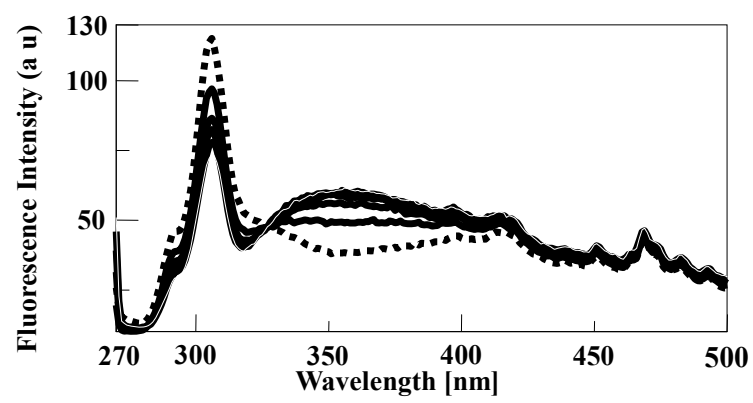

(b)

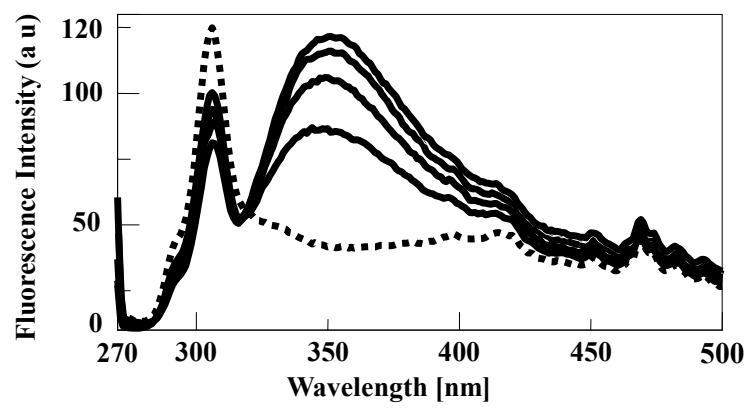

(c)

Figure 4. Effect of added mass percent of, (a) DBP, (b) DMT, and (c) DET, on excimer fluorescence quenching of PCS films at different irradiation time.

As can be observed in Figures 5 (a-c), for blended PCS with, the increase in the amount of added DBP, DMT, and DET plasticizers resulted in a decrease in the ratio of $\mathrm{I}_{[\mathrm{PH}-\mathrm{PH}]}^{\mathrm{O} /}$

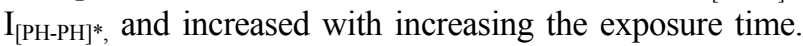
The increase in this ratio with time of irradiation indicates that the irradiation process may be accompanied by photochemical reactions in the polymeric chains. Chain scissions and photo-oxidation processes that were interpreted as a reaction involving benzene ring-opening photo-oxidation were the processes that resulted from irradiation of PS in the presence of polymeric additives [29,30]. It has been reported that the photodegradation of polystyrene films was reduced by blending with polymeric additives, as to depend on the chemical structure of the additive. $\mathrm{Wu}$ 


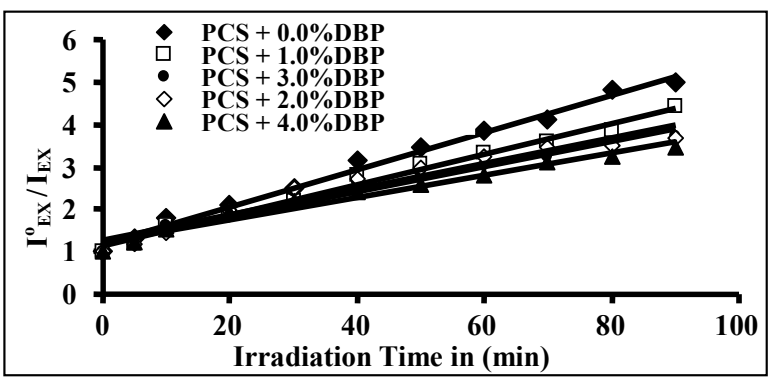

(a)

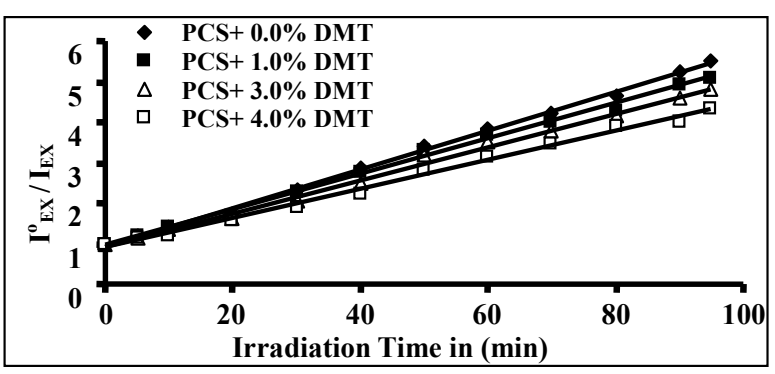

(b)

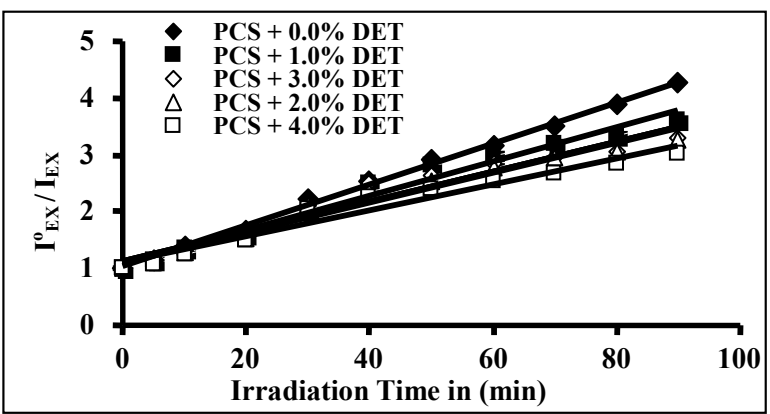

(c)

Figure 5. Effect of added mass percent of, (a) DBP, (b) DMT, and (c) DET, on excimer fluorescence quenching of PCS films at different irradiation time.

et al. [38] also studied the photo-oxidation of polystyrene by fluorescence spectra, and proposed that photo-quenching of polystyrene fluorescence was attributed to the quenching effect of peroxides formed during polymer irradiation. PCS and PBS showed lower photo- stability in comparison with other substituted polystyrene like, poly (4-methoxystyrene), Poly (4-methylstyrene) and poly (4tert-butylstyrene) in solutions [39].

Similarly, as can be observed in Figures 6(a-c), for PBS, the increase in the amount of added DMT, DET, and DOP plasticizers resulted in a decrease in the ratio of

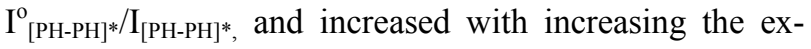
posure time.

The efficiency of photo-quenching for plasticized polymer showed a lower value than that for pure polymer, and was also found to increase with the increase in the bulkiness of plasticizer molecules.

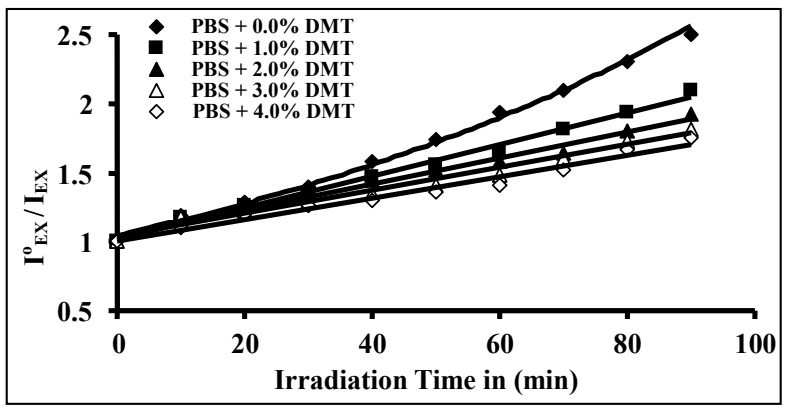

(a)

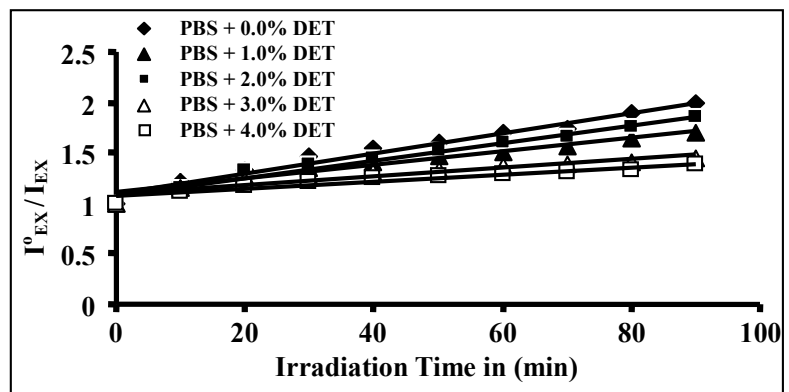

(b)

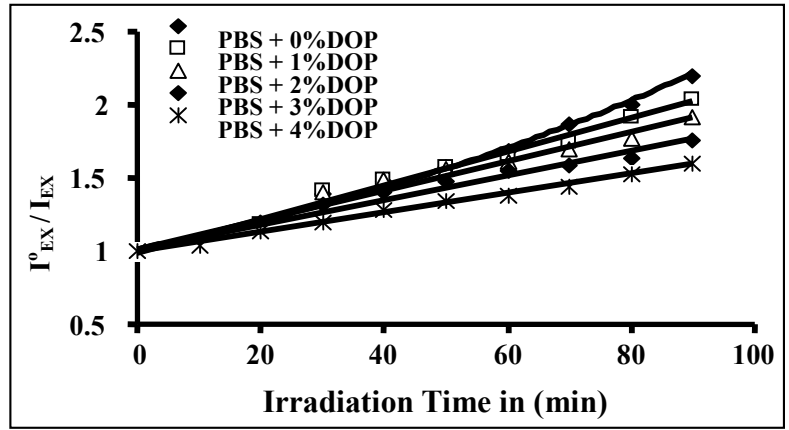

(c)

Figure 6. Effect of added mass percent of, (a) $4.0 \%$ DMT, (b) $4.0 \%$ DET, and (c) $4.0 \%$ DOP on excimer fluorescence quenching of PBS films at different irradiation time, at $(\lambda=$ $265 \mathrm{~nm})$.

From Figures 5 and 6, where the ratio $\mathrm{I}_{[\mathrm{PH}-\mathrm{PH}]^{*}}^{\mathrm{O}} / \mathrm{I}_{[\mathrm{PH}-\mathrm{PH}]^{*}}$ was plotted against different intervals of the exposure time, from the slope of the obtained lines, $\mathrm{k}_{\mathrm{PQ}}$ values were calculated for PCS and PBS plasticized with $4.0 \%$ of DMT, DET, DOT, DBP, and DOP, and are presented in Table 1.

As can be observed from Figures 5 and 6, and Table $\mathbf{1}$, the photo-quenching rate constant $\mathrm{k}_{\mathrm{PQ}}$ values, were found to increase with the increase in molar mass of the used plasticizer. Phthalate plasticizers, on the other hand, displayed a higher efficiency of photo-quenching than that which was observed by terephthalate plasticizers. This fact also correlates well with the thermal quenching of the polymers excimer fluorescence. In other words the 
Table 1. Relative Intensities of the ratio $\left(\mathbf{I}^{\mathbf{0}}{ }_{\mathrm{EX}} / \mathbf{I}_{\mathrm{EX}}\right)$ and $\mathbf{k}_{\mathrm{PQ}}$ values for the excimer fluorescence spectra of pure and blended irradiated PMXS films.

\begin{tabular}{lcllccc}
\hline & $\begin{array}{c}\lambda \text { (emis) } \\
(\mathrm{nm}) \\
\text { Polymer }\end{array}$ & $\begin{array}{c}\text { Plasticizer } \\
\text { (max })\end{array}$ & $\begin{array}{c}\text { Time } \\
(\mathrm{min})\end{array}$ & $\begin{array}{c}\left(\mathrm{I}_{\mathrm{EX}}^{\mathrm{O}} / \mathrm{I}_{\mathrm{EX}}\right) \\
\text { Irradiated }\end{array}$ & $\mathrm{k}_{\mathrm{PQ}}$ \\
\hline PCS & 316 & DMT & 0.0 & 90 & 3.85 & 0.047 \\
PCS & 318 & DMT & 1.0 & 90 & 4.02 & 0.043 \\
PCS & 321 & DMT & 3.0 & 90 & 4.60 & 0.040 \\
PCS & 323 & DMT & 4.0 & 90 & 5.05 & 0.034 \\
PCS & 321 & DET & 0.0 & 90 & 4.25 & 0.032 \\
PCS & 323 & DET & 4.0 & 90 & 3.04 & 0.019 \\
PCS & 320 & DOT & 0.0 & 90 & 3.05 & 0.038 \\
PCS & 321 & DOT & 4.0 & 90 & 3.64 & 0.026 \\
PCS & 322 & DBP & 0.0 & 90 & 4.90 & 0.044 \\
PCS & 322 & DBP & 4.0 & 90 & 3.66 & 0.026 \\
PCS & 320 & DOP & 0.0 & 90 & 4.37 & 0.034 \\
PCS & 322 & DOP & 4.0 & 90 & 3.86 & 0.028 \\
PBS & 305 & DMT & 0.0 & 90 & 2.5 & 0.011 \\
PBS & 307 & DMT & 3.0 & 90 & 1.48 & 0.008 \\
PBS & 306 & DET & 0.0 & 90 & 1.96 & 0.010 \\
PBS & 306 & DET & 4.0 & 90 & 1.30 & 0.003 \\
PBS & 305 & DOT & 0.0 & 90 & 1.65 & 0.009 \\
PBS & 307 & DOT & 4.0 & 90 & 1.44 & 0.006 \\
PBS & 306 & DBP & 0.0 & 90 & 2.55 & 0.010 \\
PBS & 307 & DBP & 4.0 & 90 & 2.04 & 0.004 \\
PBS & 304 & DOP & 0.0 & 90 & 2.05 & 0.012 \\
PBS & 306 & DOP & 3.0 & 90 & 1.48 & 0.007 \\
\hline
\end{tabular}

photo-oxidation mechanism of SPS is largely similar to the mechanism of thermo-oxidation [34].

Phthalate plasticizers, on the other hand, displayed a higher efficiency of photo-quenching than that which was observed by terephthalate plasticizers. This fact also correlates well with the thermal quenching of the polymers excimer fluorescence. In other words the photooxidation mechanism of SPS is largely similar to the mechanism of thermo-oxidation [34].

Numerous mechanisms for polystyrene photodegradation under UV-irradiation have been proposed by many authors [40-43], but a totally consistent theory is yet to be agreed upon due to the complexity of the kinetics and the formation of different photodegradation products, The mechanism of photodegradation of PCS and PBS was prepared in a similar basis and according to the results obtained from the changes in the UV-vis, fluorescence and FT-IR spectra of irradiated pure and blended PCS and PBS films, as seen in Scheme 1.

In order to describe the photodegradation processes, particular attention has been paid to the reaction steps and to the physical aspects of the degradation processes. The first step in the mechanism of photo-oxidation of PCS and PBS (Scheme 1) is a hydrogen abstraction from the polymeric backbone, which causes the formation of
Scheme 1. Photodegradation processes in the irradiated PCS and PBS films.
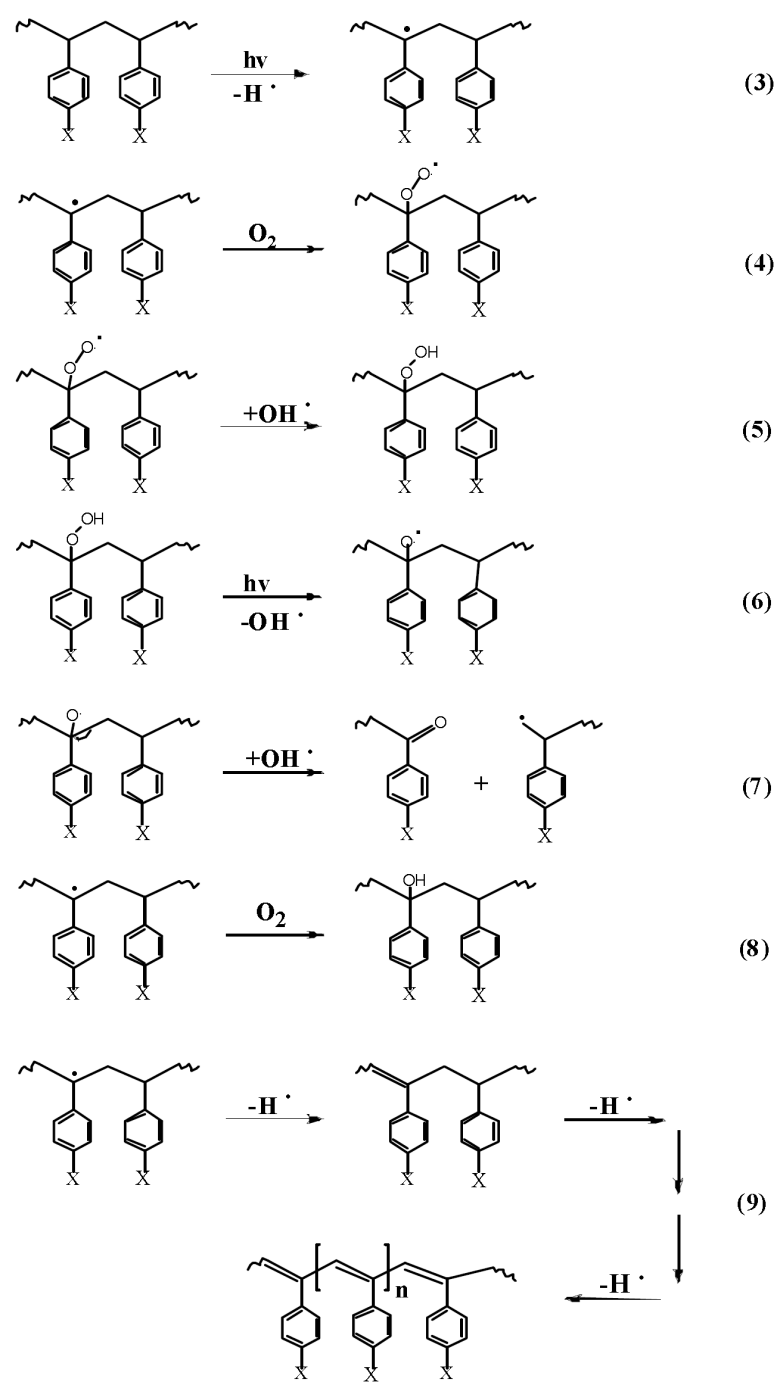

(9)
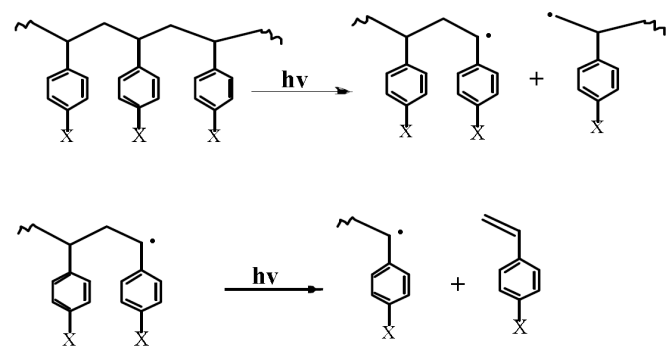

free radicals (Equation (3)) which in the presence of atmospheric oxygen, leads to the formation of peroxyradical (Equation (4)). After that, peroxyradical abstracts a hydrogen atom from the macromolecular chain to form hydroperoxide (Equation (5)). The latter was photolyzed into an alkoxy radical, which leads to chain scission with the formation of shorter chain polymer radicals and car- 
bonyl species (Equation (6)). The formed polymer free radical reacts with the hydroxyl radical to form polymer hydroxide (Equation (7)). The benzyl radical then reacts with hydroxyl radical to form alcoholic structure compound (Equation (8)). The mechanism also shows that during irradiation of polymeric chains beside chain scission, conjugated alkenes form in the aliphatic portion of polymeric chains through stable polyene radical intermediates (Equation (9)). It was reported that the formation of polyene structure in the photodegradation of polystyrene, was the major factor in yellowing in the degradation processes [22]. Random chain scission (Equation (10)) forms two macro radicals, one of which is a primary radical which is more stable then the secondary radical. The latter gives as product the substituted styrene in the first propagation step (Equation (11)).

The degradation mechanism shows that the major photo-products resulting from oxidation processes are carbonyl, hydroxyl, hydroperoxide, and conjugated alkenes. In addition to these photo-products, the benzyl radicals generated by UV-irradiation can combine with each others to result in cross-linking of polymeric chains.

A more detailed discussion on the processes involved in the oxidative degradation in a polymer film has been reported by Rabek [16]. Photo-oxidative degradation is a free radical chain mechanism which occurs when the polymer is exposed to UV-radiation in presence of oxygen. Chemical modifications have been attributed to scission of the polymer chains, and to the cross- linkages. The obtained values for the rate constant of photoquenching process for PBS are much higher than that obtained with PCS solid films. These behaviors may indicate that the stability of PBS polymer chains is much lower than that of PCS polymer chains upon irradiation with UV light. On the other hand, the stability of the collision energy transfer complex of (terephthalate-PCS)* is higher than that of (phthalate-PBS)* complex towards UV-irradiation. It is more likely that the bulkiness of blended plasticizer molecules can lower the stability of the formed energy transfer complex, and also to the exciplex activation energy for exciplex formation of the charge transfer character.

\subsection{Effect of Irradiation Time on FT-IR Spectra of Pure and Blended PCS and PBS Films}

The photodegradation mechanism is further supported by FT-IR analysis of both (PCS, PBS) and irradiated (PCS, PBS) samples. FT-IR spectra of pure PCS film as well as irradiated polymer film for $2 \mathrm{hrs}$ were obtained, and presented in Figure 7(a). The FT-IR spectra for blended PCS with $4 \%$ DOT as well as the irradiated blended polymer film with 4\% DOT are shown in Figure 7(b).

FT-IR spectra of pure PBS film as well as irradiated polymer film for 2 hrs were obtained and shown in Figure 8(a). The FT-IR spectra for blended PBS with $4 \%$ DOT, as well as the irradiated blended film with $4 \%$ DOT are shown in Figure 8(b).

As seen in Figures 7 and 8, chemical changes were assessed by FT-IR spectra for photo-irradiated of blended and pure PCS and PBS solid films. Both changes show typical functional group in the hydroxyl $3800-3000 \mathrm{~cm}^{-1}$; $\mathrm{C}-\mathrm{H}$ stretching vibration in the aliphatic chain and in aromatic rings $2800-3100 \mathrm{~cm}^{-1}$; carboxyl stretching vibration $1800-1600 \mathrm{~cm}^{-1}$; and deformation vibration $1400-$ $600 \mathrm{~cm}^{-1}$ regions.

The hydroxyl stretching vibration region showed the growth of a broad band between 3300 and $3500 \mathrm{~cm}^{-1}$ centered at $3445 \mathrm{~cm}^{-1}$, corresponding to hydroxyl groups associated with carboxylic acids. Aliphatic hydroperoxide, absorbed in the $3300-3500 \mathrm{~cm}^{-1}$ region, are also responsible for the formation of this broad band. Moreover the law intensity band at $3550-3700 \mathrm{~cm}^{-1}$ can be seen in blended PCS and PBS as shown in Figures $\mathbf{7}$ and $\mathbf{8}$, is resulting from the presence of $-\mathrm{OH}$ functional groups.

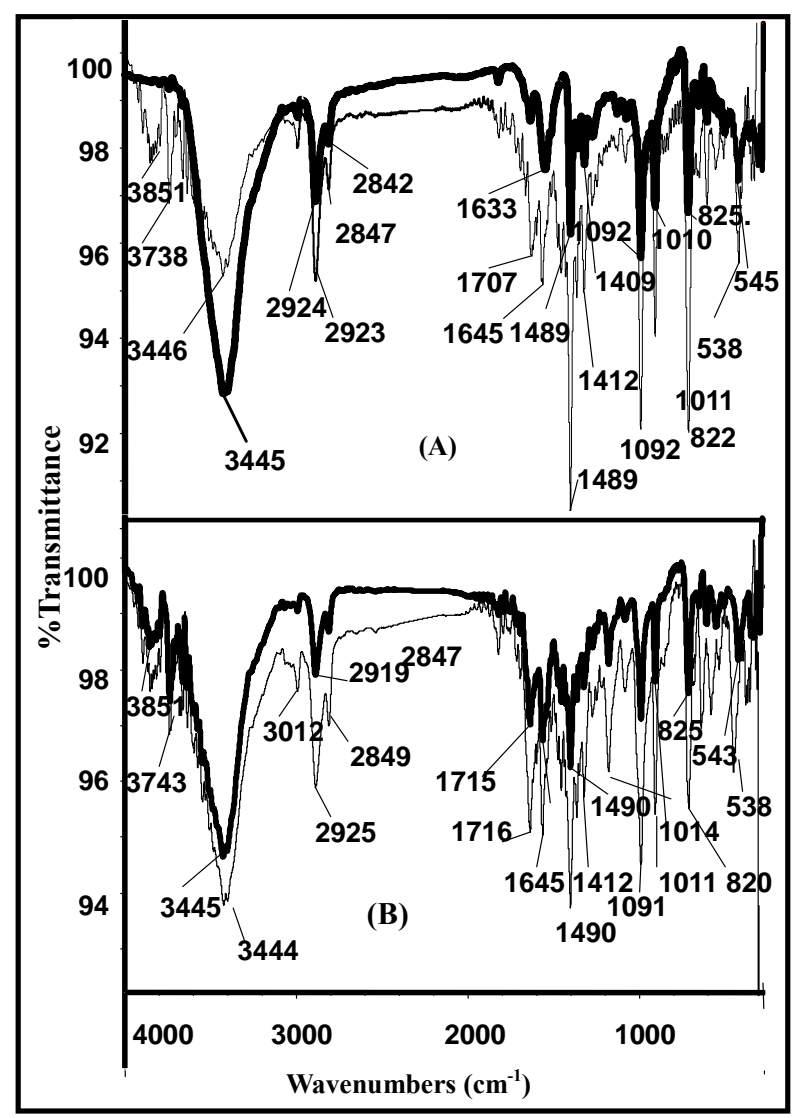

Figure 7. FT-IR spectra of (a) PCS solid film (bold) and irradiated PCS solid film for 2 hrs (fade), and (b) blended PCS with $4 \%$ DOT (bold), blended PCS with $4 \%$ DOT irradiated for $2 \mathrm{hrs}$ at $298 \mathrm{~K}$. $\left(\lambda_{\text {ext }}=265 \mathrm{~nm}\right)$ 


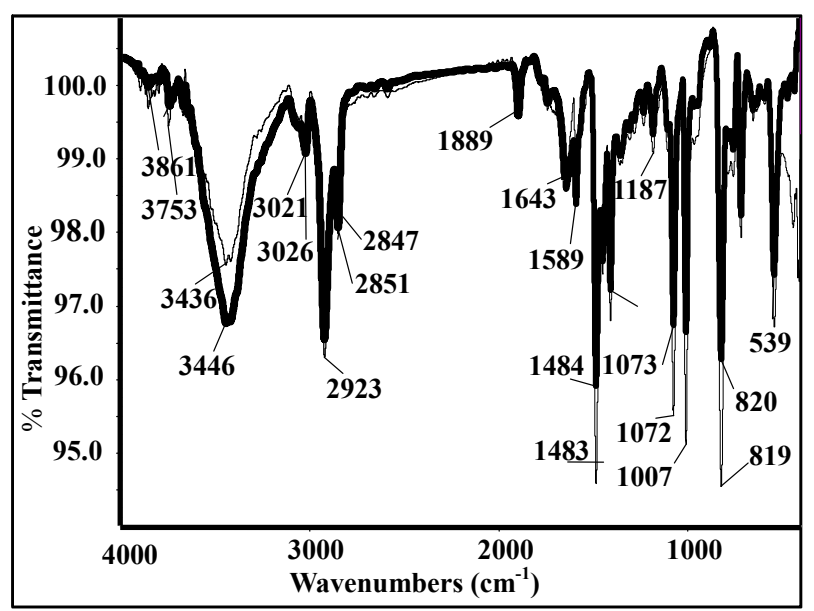

(a)

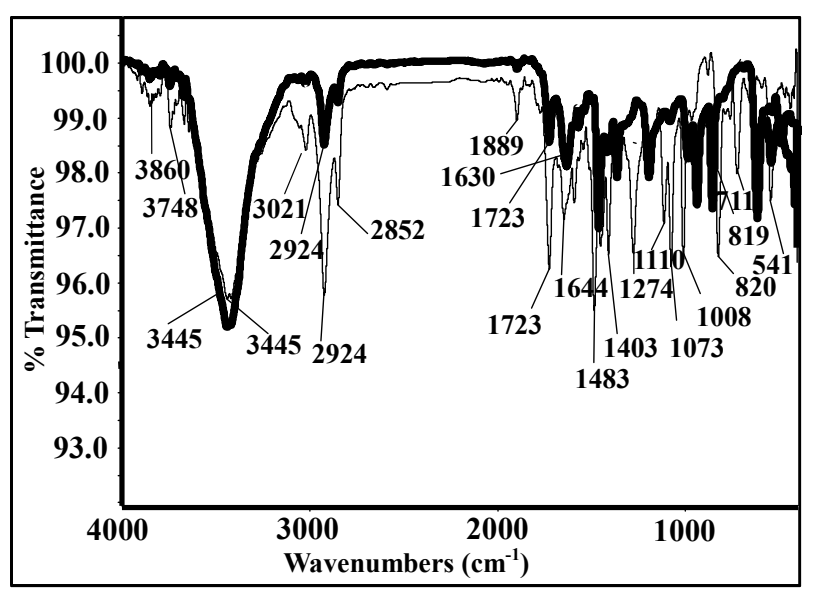

(b)

Figure 8. FT-IR spectra of (a) PBS solid film (bold) and irradiated PBS solid film for 2 hrs (fade), and (b) blended PBS with $4 \%$ DOT (bold), and blended PBS with $4 \%$ DOT irradiated for $2 \mathrm{hrs}$ at $298 \mathrm{~K}$. $\left(\lambda_{\text {ext }}=265 \mathrm{~nm}\right)$

The appearance of the 3851 and $3743 \mathrm{~cm}^{-1}$ in the irradiated blended PCS film Figure 7(b) and 3860 and 3748 $\mathrm{cm}^{-1}$ in the irradiated blended PBS film Figure 8(b), provides evidence for photo-oxidation processes occurring as a result of irradiation of polymeric films. The region 2800$3100 \mathrm{~cm}^{-1}$ shows three main bands at 3012, 2923, 2842 $\mathrm{cm}^{-1}$, and is attributed to the deformation and skeletal vibration of C-H in PCS and blended PCS. The intensity of these bands increased with blending of the polymer chains (which is similar to the bands observed in pure PCS with small red shift), indicating a less stability of the blended polymer. The same observation was noticed in case of photo-irradiated polystyrene films [44].

Photo-oxidation of irradiated PCS and PBS films leads to increase the intensity of absorbance in the bands (comparing to PCS and PBS films), at 1889, 1707, 1645, $1489,1412 \mathrm{~cm}^{-1}$ in irradiated PCS film, and bands at
$1889,1723,1644,1483,1403 \mathrm{~cm}^{-1}$ in the irradiated PBS film were observed. Bands found at 1645 and $1489 \mathrm{~cm}^{-1}$, can be ascribed to stretching vibration of the substituted benzene rings; it means that the aromatic rings lose their symmetry through the photo-oxidation processes' and are almost in the same position as observed in polystyrene spectrum [13]. The other observation in the IR-spectrum is concerned with the large increase in the relative absorption intensity in the region $\left(1610-1028 \mathrm{~cm}^{-1}\right)$, with the bands1412, 1092, and $1073 \mathrm{~cm}^{-1}$ compared to that of pure PCS and PBS films. This indicates that there is an increase in the number of $(C=C)$ that resulted from hydrogen abstraction during chains-scission process. The presence of the absorption band at $830 \mathrm{~cm}^{-1}$, as can be seen in Figure 7 and Figure 8, may suggest that the formation of conjugated double bond sequences in the main polymer chain. The same band was observed by Grassie and Weir [21] on photo-oxidation of polystyrene.

\section{Conclusions}

Based on the obtained values of absorption spectra, fluorescence quenching, and FT-IR spectra for the irradiated plasticized and Pure (PCS and PBS) solid films, the conclusions can be drawn:

1) Irradiation of PCS and PBS films in the presence of air led to significant modification to UV absorption spectra of the exposed sample. Photo-oxidation processes of polymeric chains provoked a marked increase in the absorption and a change in the shape of absorption spectra.

2) It was found that irradiation of blended PCS and PBS films at $265 \mathrm{~nm}$ resulted in a decrease in the intensity of excimer fluorescence, changes in the shape of the fluorescence spectra and the formation of new fluorescence bands at longer wavelength. This indicates that there is a possibility of photodegradation in the polymeric chains.

3) In the UV-irradiated of pure and blended PCS and PBS films (in the presence of atmospheric air), the observed increases in the carbonyl and hydroxyl regions of the FT-IR spectra, provide evidence for the photodegradation as well as the photo-oxidation of polymeric chains. The increase in the analyzed ranges can be attributed to the formation of aromatic and aliphatic ketones. It has been reported that photo-irradiation of polystyrene films with $254 \mathrm{~nm}$ resulted in the formation of carboxylic acids, esters, anhydrides, cyclic structures and other photoproducts $[36,39]$. Moreover, the photo-oxidative degradation can lead to significant formation of low molecular weight photoproducts that can migrate out of the polymer sample. The formation of low molecular weight compounds, such as benzoic acid, acetophe- 
none, benzaldehyde, formic acid, acetic acid, styrene monomer, and benzene were identified in UVirradiated polystyrene. Thus infrared analysis of the oxidative evolution of the irradiated solid sample does not permit recording the formation of all the photoproducts.

\section{Acknowledgements}

We gratefully acknowledge the financial support of Abdul Hammed Showman Foundation. Thanks are also due to Manal al buzor, Muna Hawi, May Anabtawi, and Suha Khanfar for their help in this research work, and to Professor Mikdad Al Arif for useful discussions.

\section{REFERENCES}

[1] S. S. Stivala, J. Kimum and L. Reich. "Degradation and Stability of Polymers," In: H. G. Jellinek, Ed., Aspects of Degradation and Stabilization of Polymers, Elsevier, Amsterdam, 1983, pp. 1-66.

[2] I. C. McNeill and M. Coskun, "Structure and Stability of Halogenated Polymers: Part 3-Ring Brominated Polystyrene," Polymer Degradation and Stability, Vol. 23, No. 2, 1989, pp. 175-183.

[3] I. C. McNeill and M. Coskun, "Structure and Stability of Halogenated Polymers: Part 1-Ring Chlorinated Polystyrene." Polymer Degradation and Stability, Vol. 17, No. 4, 1987, pp. 347-357.

[4] D. de Schryver, S. D. Landry and J. S. Reed, "Latest Developments on the Flame redundancy of Engineering Thermoplastics-Brominated Polystyrene in Glass Filled Engineering Thermoplastics," Polymer Degradation and Stability, Vol. 64, No. 3, 1999, pp. 471-477.

[5] F. Bertini, G. Audisio and J. Kiji, "Thermal Degradation of Chlorinated Polystyrenes," Journal of Analytical \& Applied Pyrolysis, Vol. 28, No. 2, 1994, pp. 205-217.

[6] B. Boinon, W. Abboud, A. Bouras and D. Ainad-Tabet, "Kinetics of the Thermal Degradation of Partially paraBrominated Polystyrenes," Polymer Degradation and Stability, Vol. 42, No. 1, 1993, pp. 75-80.

[7] A. Rincon and I. C. McNeill, "Thermal Degradation of Poly (Methacrylate)-Poly-4-Bromostyrene Blends and Methyl Methacrylate-4-Bromostyrene Copolymers," Polymer Degradation and Stability, Vol. 40, No. 1, 1993, pp. 125-135.

[8] I. C. McNeill and M. Coskun, "Structure and Stability of Halogenated Polymers: Part 2-Chain-Chlorinated Polystyrene," Polymer Degradation and Stability, Vol. 18, No. 3, 1987, pp. 213-224.

[9] N. Grassie, "Developments in Polymer Degradation," Applied Science Publication, London, 1977.

[10] B. Ranby and J. F. Rabek, "Studies on the PhotoOxidation Mechanism of Polymers, I. Photolysis and Photo-Oxidation of Polystyrene," .Journal of Polymer Science, Polymer Chemistry Edition, Vol. 12, No. 2, 1974, pp. 273-294.
[11] F. Bertini, G. Audisio and J. Kiji. "Thermal Behaviors and Degradation Mechanism of Brominated Polystyrenes," Journal of Analytical \& Applied Pyrolysis, Vol. 33, No. 1, 1995, pp. 213-230.

[12] H. Kaczmarek, "Photodegradation of Polystyrene and Poly (Vinyl Acetate) Blends, II. Irradiation of PS/PVAc Blends by Fluorescent Lamp," European Polymer Journal, Vol. 31, No. 12, 1995, pp. 1175-1184.

[13] Z. Zhang, X. Hu and Z. Luo, "Wavelength Sensitivity of Photo-Oxidation of Polypropylene," Polymer Degradation and Stability, Vol. 51, No. 1, 1996, pp. 93-97.

[14] H. Kaczmarek and A. Podgorski, "Photochemical and Thermal Behaviors of Poly (Vinyl alcohol) Graphite Oxide Composite," Polymer Degradation and Stability, Vol. 92, No. 6, 2007, pp. 939-946.

[15] K. R. White and A. V. Shyichuk, "Effect of Stabilization on Scission and Cross-Linking Rate Changes during Photo-Oxidation of Polypropylene," Polymer Degradation and Stability, Vol. 92, No. 11, 2007, pp. 2095-2101.

[16] J. F. Rabek, "Polymer Photodegradation, Mechanisms and Experimental Methods," Chapman and Hall, London, 1995.

[17] G. M. Fechine, M. S. Rabello and R. M. Souto-Maior, "The Effect of Ultraviolet Stabilizers on Photodegradation of Poly (Ethylene Terephthalate)," Polymer Degradation and Stability, Vol. 75, No. 1, 2002, pp. 153-159.

[18] J. Kowal and M. Nwakowska, "Photo-Oxidation of Polystyrene in Dichloromethane Solvent," Polymer, Vol. 23, No. 2, 1982, pp. 281-282.

[19] A. Torikai, T. Kobatake, F. Okisaki and H. Shuyama, "Photodegradation of Polystyrene Containing Fameretardant Wavelength Sensitivity and Efficiency of Degradation," Polymer Degradation and Stability, Vol. 50, No. 3, 1995, pp. 261-267.

[20] N. A. Weir and T. H. Milkie, "Photochemistry of RingSubstituted Polystyrenes. II. Photolysis of Poly ( $p$-Fluoro, p-Chloro, and p-Bromostyrene)," Journal of Polymer Science, Polymer Chemistry Edition, Vol. 17, No. 11, 1979, pp. 3735-3749.

[21] K. Subramanian, "Photodecomposition of Poly (Styrene Peroxide)," European Polymer Journal, Vol. 38, No. 6, 2002, pp. 1167-1173.

[22] G. Geuskens, P. Bastin, Q. Lu-Vinh and M. Rens, "PhotoOxidation of Polymers: Part IV-Influence of the Processing Conditions on the Photo-Oxidation Stability of Polystyrene," Polymer Degradation and Stability, Vol. 3, No. 4, 1981, pp. 295-306.

[23] K. C. Tse, F. M. Ng and K. N. Yu, "Photodegradation of DAVC by UV-Radiation at Various Wavelengths," Polymer Degradation and Stability, Vol. 91, No. 10, 2006, pp. 2380-2388.

[24] P. C. Lucas and R. S. Porter, "Auto Inhibition in Polystyrene Photo-Oxidation," Polymer Degradation and Stability, Vol. 26, No. 3, 1989, pp. 203-208.

[25] A. Torikai, T. Takeuchi and K, Fueki, "Photodegradation of Polystyrene and Polystyrene Containing Benzophe- 
none," Polymer Photochemistry, Vol. 3 No. 4, 1983, pp. 307-320.

[26] W. M. Choi, I. D. Jung, C. Sik and W. Cho, "Synthesis and Properties of Photodegradable Polystyrene-Containing Carbonyl Group," Journal of Applied Polymer Science Vol. 67, No. 7, 1998, pp. 1237-1242.

[27] A. E. Ramadhan, R. K. Ahmed and K. E. Al Ani, "Thermal Effect and Quenching of Exciplex Fluorescence of Polystyrene Derivatives by Dimethyl Terephthalate in Solid Films," Polymer Journal, Vol. 38, No. 4, 2006, pp. 355-363.

[28] K. E. Al Ani and M. A. Hawi, "Effect of Plasticization on the Photodegradation of Poly (para-Methoxystyrene) Films," Journal of Material Science, Vol. 44, No. 10, 2009, pp. 2674-268.

[29] S. Stokes and R. B. Fox, "Photolysis of Poly- $\alpha-$ Methylstyrene," Journal of Polymer Science, Vol. 56, No. 2, 1962, pp. 507-517.

[30] N. A. Weir, "Photolysis of Poly (p-Methylstyrene)," Journal of Applied polymer Science, Vol. 17, No. 2, 1973, pp. 401-419.

[31] V. V. Zuev, P. V. Zgonnik, L. D. Turkova and L. A. Shibaev, "Thermal Degradation of Poly ( $p$-Nitrostyrene)," Polymer Degradation and Stability, Vol. 63, No. 1, 1999, pp. $15-17$.

[32] E. K. Fields and S. Meyerson, "Advances in Free-Radical Chemistry," Elek Science, London, 1975.

[33] K. E. Al Ani and A. M. Suleiman, "Substituent Effect on Fluorescence Quenching of Polystyrene Derivatives by Polymeric Plasticizers," Journal of Photochemistry, A, Chemistry. Vol. 188, No. 2, 2007, pp. 177-184.

[34] K. E. Al Ani, M. Al Barghouthi and M. Buzour, "Solvent Effect on Thermal Degradation of Plasticized paraSubstituted Polystyrenes," Polymer Degradation and Stability, Vol. 91, No. 12, 2006, pp. 3252-3258.

[35] K. E. Al Ani, Y. Yousef and T. Akasheh, "Effect of Solvents on Fluorescence and Fluorescence Lifetimes of $p$ -
Substituted Polystyrenes," Asian Journal of Chemistry, Vol. 18, No. 3, 2006, pp. 1675-1684.

[36] C. David, D. Baeyens-Volant, G. Delaunois, Q. Lu-Vinh, W. Piret and G. Geuskens, "Photo-Oxidation of Polymers-III Molecular Weight Changes in the Photolysis and Photo-Oxidation of Polystyrene," European Polymer Journal, Vol. 14, No. 7, 1978, pp. 501-507.

[37] K. E. Al Ani and A. E. Ramadhan. "Study of the Influence of UV-Irradiation on the Photodegradation of Plasticized Poly (para-Tert-Butylstyrene) Films," International Journal of Material Research, Revised, 2010.

[38] S. K. Wu, L. H. Liu and G. S. Dai, Polymer Communications, Vol. 2, No.2 ,1984, p.153.

[39] K. E. Al Ani and A. E. Ramadhan, "Photodegradation of Plasticized Poly (para-Substituted Styrene) in Solution," Polymer Degradation and Stability, Vol. 93, No. 8, 2008, pp. 1590-1596.

[40] N. A. Weir, "Reactions of Hydroxyl Radical with Polystyrene," European Polymer Journal, Vol. 14, No. 1, 1978, pp. 9-14.

[41] E. P. Otocka, S. Curran and R. S. Porter, "PhotoOxidation of Polystyrene: Irradiation at 254 and $365 \mathrm{~nm}$," Journal of Applied Polymer Science, Vol. 28, No. 10, 1983, pp. 3227-3233.

[42] T. Tamai, I. Hashida, N. Ichinose, S. Kawanishi, H. Inoue and K. Mizuno, "UV-Irradiation of Thin Film of Polystyrene Derivatives: Formation of Carboxylic Group and Cross-Linking from 4-Trimethylsilylmethyl Substituent," Polymer, Vol. 37, No. 24, 1996, pp. 5525-5528.

[43] M. D. Millan, J. Locklin, T. Fulghum, A. Baba and R. C. Advincula, "Polymer Thin Film Photodegradation and Photochemical Cross-Linking FT-IR Imaging Evanescent Waveguide Spectroscopy, and QCM Investigation," Polymer, Vol. 46. No. 15, 2005, pp. 5556-5568.

[44] H. Kaczmarek, A. Felczak, A. Szalla, "Studies of Photochemical Transformation in Polystyrene-maleic Anhydride Copolymer," Polymer Degradation and Stability, Vol. 93, No. 7, 2008, pp. 1259-1266. 